\title{
Application of biomonitoring technology in environmental engineering based on model groups of amphibiontic organisms (insecta: odonata)
}

\author{
Sergey Kozminov, Khasan Ketenchiev, Anzor Paritov, Elena Krapivina, and Bela Sunsheva
}

Kabardino-Balkarian State University named after H.M. Berbekov, st. Chernyshevsky, 173, 360004

Nalchik, Russia

\begin{abstract}
The paper presents the results of the analysis of the use of amphibiontic organisms as bioindicators of the ecological environment, as model groups in ecological engineering. The solution to the conceptual problem of ecological engineering in the conservation of biological diversity is to take an inventory of natural, urbanized and agroecosystems. Among amphibiotic insects, the order Odonata stands out, with morphological plasticity, biological progress, adults and dragonfly larvae actively colonize aquatic and terrestrial ecosystems of various types. When moving to habitat in mountain biotopes, the linear body dimensions of dragonfly larvae of the species L. depressa L., S. meridionale Selys, C. puella L. decrease, which indicates unfavorable, contrastingly changing habitat conditions in mountain ecosystems. The taxonomic composition of dragonflies in lowland water bodies is represented by the suborders Anizoptera ( 7 species), Zygoptera (5 species), Caloptera (1 species). In the foothill water bodies - Anizoptera (5 species), Zygoptera (4 species), Caloptera (1 species), in mountain water - Anizoptera (4 species), Zygoptera (2 species). Most of the dragonfly taxa are characteristic of the plains and foothills with eutrophied biotopes characteristic of polysaprobic reservoirs with heavy pollution. In oligosaprobic biotopes, with little or no organic pollution in the water, dragonflies Ae. cyanea Müller and C. splendens Harris. The confinement of species to certain habitats, characterized in varying degrees of pollution by organic substances and their oxidation products, makes it possible to use dragonflies as bioindicators and organize background monitoring of ecosystems in the Central Caucasus.
\end{abstract}

\section{Introduction}

At present, the problem of preserving the species diversity of living organisms and the rational use of natural resources is quite acute. Protection of the surrounding world should be based on the integration of various approaches, on the basis of a comprehensive study of the interaction of all levels of organization of wildlife [1]. A solution is possible with the adoption of measures to ensure the long-term functioning and stability of all types of ecosystems, disturbed and undisturbed by anthropogenic impact. The impact of negative 
technogenic processes on biological diversity, sustainable development and functioning of ecosystems, defines environmental safety as the protection of the environment [2]. In this regard, environmental engineering is designed to solve a number of environmental and biological problems to ensure the preservation of taxonomic diversity, to reduce various types of pollution on ecosystems.

As a system of scientific and engineering activities, environmental engineering solves the problems of ensuring environmental quality control measures for the environment of aquatic and terrestrial ecosystems, the distribution and preservation of habitats of various groups of living organisms, environmental monitoring and the long-term existence of all types of natural biotopes with their plant communities and animal populations.

One of the conceptual tasks of ecological engineering is the conservation of biological diversity, based on fundamental research on the inventory of natural, urbanized and agroecosystems that ensure the transformation and circulation of matter and energy from producers to the highest trophic levels. In this aspect, ecological monitoring seems to be important, providing constant monitoring of the functioning of ecosystems with a recreational load, as well as existing natural, or reserves, providing an inflow of biological resources for reproduction used by ecological engineering. Biological control of the quality of the environment can be one of the key methods of environmental engineering, the solution of which is the search for model groups of living organisms that are sensitive to changes in the ecological environment and their components, which are bioindicators of pollution. On the basis of environmental monitoring, it is possible to resolve issues of environmental safety, as well as to comply with the norms and principles of rational use of natural resources [3].

Based on biomonitoring, it is possible to fundamentally improve the tracking scheme for the state of ecosystems of any type. In this regard, the most interesting is the group of amphibiontic organisms, as it is wholly dependent in its development, both on the aquatic and terrestrial-air environment. Among all amphibiontic organisms, the most interesting are amphibiontic insects, which in many water bodies, their ecosystems and biotopes dominate in terms of quantitative indicators, biomass and number of species [4]. Among all amphibiotic insects, the order of dragonflies Odonata stands out, known for its morphological plasticity, biological progress, high mobility of adults, and habitation in intrazonal biotopes, whose representatives occupy the niche of active predators $[5,6]$. Adults and larvae of dragonflies actively colonize aquatic and terrestrial, both natural and urbanized ecosystems of various types, actively transform matter and energy from lower trophic levels to higher ones. It is also important that dragonflies play an important role in the destruction of blood-sucking insects, larvae and imago of mosquitoes, which are carriers of pathogens of various diseases [7].

The imaginal and preimaginal phases of dragonflies, as the most important component of living nature, are interconnected with both biotic and abiotic factors, which are determined by relationships with other living organisms and the inorganic environment [8, 9] and developed on model species and their populations [10]. Most taxa of dragonflies are quite sensitive to changes in the physicochemical composition of the habitat, drainage of reservoirs, regulation of river flow and deterioration of water quality, which makes it possible to use the potential bioindicator role of dragonflies, as well as to compile lists of rare and endangered species in aquatic and terrestrial ecosystems [11, 12].

Biological control of water quality in the Central Caucasus is a problem, the solution of which is to preserve the biodiversity of aquatic and terrestrial ecosystems of the unique mountainous and historically formed region. The anthropogenic effect on natural ecosystems has caused significant damage to the fauna of various groups of animals, including many rare, endemic and relict taxa of the Caucasus. Dragonflies, leading an amphibiotic lifestyle, being one of the mass components of aquatic and near-aquatic 
biocenoses, interact with both organic and inorganic environments, are exposed to the nature and varying degrees of pollution of natural ecosystems with organic and inorganic substances and their compounds, products of their decay as a result of oxidative-restorative reactions.

Based on the most important relevance of understanding the bioindicator role of dragonflies in environmental monitoring of ecosystems disturbed and undisturbed by anthropogenic impact, application in environmental engineering, we set a goal for the study: to analyze the distribution and composition of the dragonfly community in a comparative aspect, to determine the taxonomic composition, some ecological, biological and adaptive features, to determine the possibility of different taxa for use in background monitoring, in bioindication of the qualitative composition of the natural environment.

\section{Materials and Methods}

This work is based on the materials obtained earlier [3, 13-17] and additionally processed with the specification of the original materials and literature sources [18-20]. The study of the distribution of dragonflies by the altitudinal-belt and horizontal vector, the determination of the types of environmental indicators was carried out on various terrestrial, near-water and water plains (up to $500 \mathrm{~m}$ above sea level), foothill $(500-1000$ $\mathrm{m}$ above sea level) and mountain $(1000-2500 \mathrm{~m}$ above sea level) ecosystems of the Central Caucasus of various origins in the Kabardino-Balkarian Republic. When carrying out field work, which was carried out during the growing season, the route method $(100 \mathrm{~m})$ was used, as well as harvesting of areas of $10-15 \mathrm{~m}^{2}$. Collection, species identification and office processing were carried out according to generally accepted methods of entomological research [21-24]. To clarify the original materials, study the ecological and biological features and check the taxonomic affiliation in laboratory conditions, dragonfly larvae (about 3.5 thousand specimens in total) were kept, which were additionally processed.

\section{Results and Discussion}

When determining the types of bioindicators, it is necessary to take into account not only high morphological plasticity, but also many biological features, such as seasonal variability, summer time, habitats, leading to the differentiation of the species composition. Dragonflies form communities under the influence of physical and geographical conditions, which is associated with the biological characteristics of the species. The influence of biological features primarily affects the penetration of species of southern origin into the mountains, the northern ones can live only in the mountains, and if they descend into the foothills, then only to an insignificant extent [25]. Adults of dragonflies are found in different geographic zones with a sharp decrease in the number of species, while species of northern origin are susceptible to extinction, which illustrates various stages of the general process [26]. At the same time, under the influence of physical and geographical conditions, there is an adaptive variability of the morphology of dragonflies, the color of the body and their parts, the features of the structure of the wings [27, 28]. The distribution of dragonfly larvae entirely depends on the dynamics of water temperature, the abundance and composition of the food supply, the depth and flow of the reservoir. The location of reservoirs with sufficient depth in the lowering of the relief, the overgrowing of the banks with shrubs, contributes to the experience of the unfavorable conditions of the winter period by the larvae, which were subordinate to the heating of the water and the natural food base. [29]. According to the nature of habitats, the preimaginal stage is divided into 4 groups: 
inhabitants of exclusively stagnant water bodies, mainly stagnant, mainly flowing and flowing water bodies [30].

When studying the composition of the species composition, distribution, composition of communities, ecological, biological and adaptive characteristics of various taxa to aquatic and terrestrial habitats, it is necessary to clearly define the boundaries of the species range, which is the result of the action of various factors, their complex and the confluence of historical events and evolution. Most species of dragonflies strive to expand the living space that they occupy, interact with the environment according to the rule of limiting factors that move away from the optimum ecological habitat of the species, limiting its existence in new ecological conditions. The limiting factors affecting dragonflies are very diverse, they include both abiotic and biotic and anthropogenic ones. The quick response of dragonfly larvae and imago to these factors is determined and depends on their hereditary characteristics, which determine the optimum needs of the species, its rate of response to changes in environmental factors and their complexes.

When analyzing the distribution, ecological and biological characteristics of dragonflies, it is necessary to take into account the peculiarities of the amphibiontic way of life, which determines a number of restrictions for full development and metamorphosis. At the same time, dragonfly larvae are more dependent on changes in environmental conditions than adults [18], which affects the data obtained on the distribution, composition and structure of the dragonfly community, their discrepancy in taxonomic, quantitative and qualitative indicators.

The basis of the dragonfly fauna of the Central Caucasus is formed by the autochthonous core of taxa, which was formed by historical interacting factors, such as: a warm climate favorable for the habitation and development of dragonflies; a sufficiently optimal humidity regime for the passage of an amphibiotic lifestyle; mountainous relief, which created the whole range of local water and near-water stations with various ecological conditions.

Changes in the ecological habitat that exert strong pressure on dragonflies have both negative and positive effects. The negative impact is determined not only in the destruction of water bodies necessary for the development of the preimaginal phase, but also in their pollution, destruction of breeding sites and limitation of the full development cycle to metamorphosis. The positive side of anthropogenic impact is the creation of new reservoirs in artificial and agroecosystems, which are suitable for the development of larvae, metamorphosis and emergence of adults, which subsequently colonize near-water and terrestrial ecosystems. Therefore, the development and rather rapid colonization of artificial reservoirs by representatives of dragonflies indicates the possibility of faunistic movements and a sharp change in the historically established community of dragonflies. The assimilation of artificial ecosystems of various types and purposes by dragonflies occurs not only due to taxa characteristic of the territory, but also due to species southern in origin that do not previously populate natural ecosystems, changing the species composition, but in general the biological diversity of dragonflies. This determines the fundamental foundations of studies of faunistic movements, species diversity, adaptive, ecological and biological characteristics, the search for species of bioindicators of the natural environment, both among adults and larvae of dragonflies.

The preimaginal phase of dragonflies prefers to develop in small reservoirs or biotopes, which are characterized by strong ecological vulnerability and even complete extinction. A negative factor for dragonflies is the habitation of the preimaginal and imaginal stages of development in different biotopes, a long development cycle, and anthropogenic pollution, leading to the degradation of aquatic ecosystems. A number of factors affect the imago of dragonflies: death from pesticides when processing agricultural systems, road transport when flying over highways, as well as a large catch by collectors. 
The main abiotic factor that determines and restrains the spread of dragonflies in ecosystems is the temperature regime of water bodies, which are habitats where the preimaginal phase develops up to the emergence of adults. The distribution of dragonflies along the altitude vector, within each altitudinal belt, is heterogeneous, determined by the ecological, biological and adaptive characteristics of various species, their developmental biology and the ability to interact with various abiotic factors. Dragonflies, as ectothermic organisms, are entirely dependent on external energy sources, and their adaptive and regulatory capabilities are limited [31]. Therefore, the taxonomic composition, distribution and structure of the dragonfly community depends on temperature and its dynamics for a long time, which also affects the biomass of the natural food base, the rate of metabolism and ontogenesis of individual preimaginal stages. Dragonflies are quite resistant to various temperatures, which is determined by avoiding low temperatures, since they spend the winter in water bodies. In this case, the emergence of adults in the north occurs later than in the southern regions, and in a harsh climate, a transition to habitat in biotopes with stagnant water, which warms up better, is noted [18]. Although the distribution of dragonflies is entirely dependent on temperature, this dependence is much less than that of other land dwellers, so the temperature factor has to be given close attention.

Analysis of the temperature regime of water bodies in the altitudinal-zonal aspect shows a certain discrepancy both in the temperature dynamics of aquatic ecosystems and a shift in the maximum temperature achievement towards the summer period, which affects the decrease in the quantitative and qualitative indicators of the natural food supply of dragonfly larvae. In the Central Caucasus, the shift in the beginning of the growing season towards the summer period from the plain to the mountainous zone $(1-2$ months $)$ leads to a decrease in the temperatures of aquatic ecosystems of the mountains $\left(5-10^{\circ} \mathrm{C}\right)$ [32]. When dragonfly larvae move into the mountain zone, either an increase in the number of individual stages occurs, with a decrease in the development time, or an increase in the duration of development of stages, with a general decrease in the size of the body and their parts. We noted a decrease in body size in the larvae of dragonflies of the species Libellula depressa L., Sympetrum meridionale Selys, Coenagrion puella L., when moving to habitat in water bodies of the mountain zone, which indicates rather unfavorable, contrastingly changing habitat conditions in mountain ecosystems, as well as adaptive plasticity of these taxa of southern origin. Species of northern origin, such as Aeshna cyanea Müller, which create isolated areas [18], develop preimaginal in low-temperature mountain water bodies, although actively mobile imago occurs in the foothill zone, or can fly into the plain.

Characterization of the natural food base is important for determining the taxonomic composition and community of dragonflies. Representatives of different suborders, although they are predators, have their own local food spectra. The species composition of the suborder Anisoptera consists of fairly large forms, the natural food supply of which in mountain conditions is sufficient in quantity and quality for the development of the preimaginal and imaginal stages. The food base of representatives of the suborder Zygoptera is based on zooplankton, which sharply depletes its quantitative and qualitative indicators in foothill and mountain water bodies. At the same time, the younger preimaginal stages feed exclusively on zooplankton with a low individual biomass, whose representatives, under conditions of a short growing season and low water temperatures, deplete the taxonomic composition and have a local occurrence with specific physicochemical conditions of water composition [32]. It should be noted that the presence of near-water and aquatic vegetation has a direct impact on the taxonomic and quantitative composition of dragonflies Zygoptera, whose larvae and adults use vegetation as a substrate for metamorphosis, or shelter and rest [21,33]. The qualitative composition of vegetation has little effect on dragonflies [18]. Dragonflies of the suborder Anizoptera, among which there are many forms of larvae leading a near-bottom lifestyle, are not very susceptible to 
the nature of vegetation change. However, the structure of the soil in terms of such indicators as the inclusion of silt and detritus in the composition, the formation of its complex, is formed as a result of the presence of near-water and aquatic vegetation. The composition of the natural food base is determined by quantitative indicators and biomass of vegetation, their influence on the composition of nutrients in water, the development of zooplankton and other forms of invertebrates, benthic organisms, which are food objects for dragonfly larvae and the successful passage of the entire life cycle.

The distribution of dragonflies along the altitude and horizontal vector, their occupation of habitats convenient for habitation, is determined by the river network with permanent inland and floodplain water bodies. It is the basin of any river with its complex hydrological system that creates an arena of life for dragonflies, ensures the development and movement of individuals of the species within it. The mineral composition of the water has little effect on dragonflies, the preimaginal stage can tolerate its small size and are not tied to it [18]. The rather weak mineralization of the water bodies of the Central Caucasus is determined by the complex belonging to the hydrocarbonate class of the calcium group, which has little effect on the distribution of dragonflies and their ecological and biological features.

Continental water bodies of any type are divided into groups according to the nature of pollution by organic substances, products of their oxidation and decay [34, 35]. A quantitative and qualitative analysis of water bodies by the altitude vector of the Central Caucasus shows a significant discrepancy both in the availability of convenient aquatic biotopes for dragonflies to inhabit, and in the nature of saprobity, or pollution by organic substances. Water bodies of the plain, to a lesser extent of the foothills, consist of polysaprobic and mesosaprobic biotopes. Rare oligosaprobic biotopes are represented inhomogeneously and are fed from spring waters, or are formed as a result of ice melting. The aquatic ecosystems of the mountains mainly consist of oligosaprobic biotopes. Rare polysaprobic and mesosaprobic biotopes are various shallow bays, backwaters, or temporary puddles. The discrepancy in the gradient of the saprobity of water bodies in the plain, foothill and mountain zones is associated with the descent of oxygen-rich glacial waters into the plain zone, the accumulation of various organic substances on its way and the warming up of water. The distribution of the taxonomic composition of dragonflies showed that dragonfly larvae belonging to the suborders Anizoptera (7 species), Zygoptera (5 species), Caloptera (1 species) live in lowland water bodies, Anizoptera (5 species), Zygoptera (4 species), Caloptera (1 species) in foothill water bodies, in the mountains Anizoptera (4 species), Zygoptera (2 species). Most of the taxa are characteristic of the plains and foothills; their habitats are associated with eutrophied biotopes characteristic of polysaprobic water bodies with heavy pollution. For them, the most characteristic indicator species are: Libellula depressa L., Sympetrum meridionale Selys, Orthetrum cancellatum L., O. albistylum Selys, Crocothemis erythraea Brulle, Coenagrion puella L. For mesosaprobic biotopes with moderate pollution, the following are typical: Lestes sponsa Hansemann, L. dryas Kirby, C. pulchellum Van der Linden, Platycnemis pennipes Pallas, Anax imperator Leach, Erythromma najas Hansemann. Oligosaprobic biotopes with little or no organic pollution in the water are characterized by the larvae of the dragonflies Aeschna cyanea Müller and Calopteryx splendens Harris.

The confinement of dragonflies to certain biotopes, differing in the nature of saprobity, as well as in the altitude vector, can be associated not only with the ecological characteristics of various taxa to experience unfavorable conditions and develop in different physicochemical composition of the aquatic environment, but also be associated with biological processes and conditions of their course. One of the most important phenomena characterizing the dragonfly community and its taxonomic composition is metamorphosis, emergence and expansion of imago carrying a reproductive function, which determines the 
possibility of dragonfly spreading and the development of new habitats and territories. he main external environmental factor that determines the beginning and termination of emergence, summer of adults, and its period is the average daily air temperature [20], as well as with temperature dynamics during the growing season and the achievement of optimal values. Comparison of the time of metamorphosis and the temperature of water and air showed that the main emergence of adults is associated with a shift from the end of April to June from the plain to the mountains, when the water warms up to $16-18{ }^{\circ} \mathrm{C}$. At the same time, on the plain and foothills, the maximum air temperature was in the range of $21-23{ }^{\circ} \mathrm{C}$, and in the mountainous zone $-18-20{ }^{\circ} \mathrm{C}$ [32]. The hatching of adults is associated with the individual ecological and biological characteristics of various taxa, the ability to adapt to the temperature dynamics of different water bodies and terrestrial ecosystems and their origin. Metamorphosis and emergence is associated with the individual ecological and biological characteristics of various taxa, their origin and historical development. The formation of the faunistic complex, as well as the composition of populations and communities of dragonflies, is deeply associated with ecological and biological adaptations not only to survival in changing habitat conditions, but also to the possibility of settling new habitats, both along the altitude and horizontal vectors.

\section{Conclusion}

The formation of the larval population, communities of adult dragonflies, the distribution of taxa in various terrestrial and aquatic biotopes is determined by the interaction of physicochemical complexes, the factor of the habitat and the ecological and biological characteristics of different species. Cognition of such interaction will determine the ways and possibilities of using the preimaginal and imaginal phases of development as a model group for ecological monitoring of ecosystems. The taxonomic composition of dragonfly populations clearly determines the pollution of the environment, natural ecosystems, agroecosystems and their stations. The confinement of certain species to certain habitats, characterized in varying degrees of pollution by organic substances and products of their oxidation, makes it possible to use dragonflies of 14 species as bioindicators and organize background monitoring of ecosystems in the Central Caucasus. As amphibiontic organisms of dragonflies clearly capture changes in the aquatic and ground-air environment, are associated with abiotic factors and their dynamics. Given the wide territorial distribution of agroecosystems, it is possible to use them as a reserve of rare and protected species $(A$. imperator Leach, L. depressa L., C. puella L., L. sponsa Hansemann, L. dryas Kirby), endangered $[36,37]$. Taking into account the interaction of habitat conditions and biology of larvae, as well as adults of dragonflies, it is possible to determine a complex of favorable and unfavorable factors for the development of dragonflies. Each of the factors interacts with each other and does not determine the composition of populations, natural communities, and the biology of individual taxa. They dynamically act through all life cycles on the biodiversity of dragonflies in ecosystems, determine the possibility of development of dragonflies not only in their usual habitats, but also to populate newly formed ones.

\section{References}

1. A. V. Yablokov, S. A. Ostroumov, Wildlife Conservation: Problems and Prospects (1983)

2. A. B. Savinov, V. A. Basurov, Bulletin of the Nizhny Novgorod University. N.I. Lobachevsky, Biology, 3(1) (2014) 
3. E. A. Krapivina, S. G. Kozminov The use of model groups of living organisms in ecological monitoring of ecosystems in the western part of the Central Caucasus (2013)

4. S. M. Golubkov, Functional ecology of amphibiotic insect larvae (2000)

5. B. B. Rodendorf, Infraclass Libellulones (1980)

6. B. N. Shvanvich, General entomology course (1949)

7. B. F. Belyshev, A. Yu. Kharitonov, S. N. Borisov, Fauna and ecology of dragonflies (1989)

8. C. L. Pierce, P. H. Crowley, Ecology, 66, 5 (1985)

9. C. Blois, A. Cloares, Z. Tierpsychol, 68, 4 (1985)

10. V. M. Titar, S. S. Kulchitsky, Population monitoring of the zone of anthropogenic impact on the example of two species of dragonflies (1989)

11. F. L. Carle, Odonatologica 8, 4 (1978)

12. N. Gaithier, Rhone-Alpes nature, 24 (1990)

13. Kh. A. Ketenchiev, S. G. Kozminov, Z. Kh. Gemueva, A. A. Alakulova, South of Russia: ecology, development, 12, 4 (2017)

14. Kh. A. Ketenchiev, A. Yu. Kharitonov Dragonflies of the Mediterranean (1999)

15. S. G. Kozminov, Kh. A. Ketenchiev Dragonfly larvae as bioindicators of aquatic ecosystems (1999)

16. Kh. A. Ketenchiev, A. Yu. Kharitonov, S. G. Kozminov, T. A. Avtaeva, Sh. A. Kushalieva, Dragonflies of the Mediterranean faunal subregion of the Paleosubtropical region of the Boreal kingdom (2020)

17. S. G. Kozminov, Z. A. Kubatieva, Grozny natural science bulletin 5, 1 (19) (2020)

18. B. F. Belyshev, A. Yu. Kharitonov, Geography of dragonflies (Odonata) of the Boreal faunal kingdom (1981)

19. B. F. Belyshev, A. Yu. Kharitonov Geography of dragonflies (Odonata) of the Meridian faunal kingdom (1983)

20. B. F. Belyshev, A. Yu. Kharitonov, S. N. Borisov, Fauna and ecology of dragonflies (1989)

21. A. N. Popova, Dragonfly larvae of the fauna of the USSR (Odonata) (1953)

22. B. F. Belyshev, A. Yu. Kharitonov, Keys to dragonflies by their wings (genera of the Boreal faunistic kingdom and adjacent lands, species of fauna of the USSR) (1977)

23. Kh. A. Ketenchiev, A. Yu. Kharitonov, Keys to the Caucasus dragonflies (1998)

24. K. K. Fasulati, Field study of terrestrial invertebrates (1971)

25. A. N. Bartenev, Bulletin of the State Museum of Georgia, 2 (1925)

26. A. N. Bartenev, Proceedings of the North Caucasian Association of Scientific Research of Innovators, 72, 14 (1930)

27. A. N. Bartenev, Works of the North Caucasian Hydrobiological Station, 3, 1 (1930)

28. A. N. Bartenev, Works of the North Caucasian Hydrobiological Station, 3, 3 (1930)

29. A. Yu. Kharitonov, Ecology, 3 (1975)

30. E. S. Shalopenok, Distribution features of dragonfly larvae in water bodies of different types (1989)

31. M. Bigon, J. Harper, K. Townsend, Ecology. Individuals, populations and communities (1989) 
32. S. G. Kozminov, Distribution and ecology features of dragonfly (Odonata) larvae in the Central Caucasus (2019)

33. W. I. Lucas, The aquatis (naiad) Stage of the British dragonfiies (Paraneuroptera) (1930)

34. E. N. Pavlovsky, S. G. Lepneva, Essays on the life of freshwater animals (1948)

35. L. I. Kotova, L. P. Ryzhkov, A. V. Polina, Biological control of water quality (1989)

36. Red Book of the RSFSR (animals) (1983)

37. Red Book of the Kabardino-Balkarian Republic (2000) 